\title{
Associations between stress and migraine and tension-type headache: Results from a school-based study in adolescents from grammar schools in Germany
}

\section{I (7) 774-785}

(C) International Headache Society 201 I

Reprints and permissions:

sagepub.co.uk/journalsPermissions.nav DOI: I0.1।77/0333102410390397

cep.sagepub.com

(SAGE

\author{
Astrid Milde-Busch', Astrid Blaschek ${ }^{2}$, Florian Heinen ${ }^{2}$, \\ Ingo Borggräfe ${ }^{2}$, Inga Koerte ${ }^{3}$, Andreas Straube ${ }^{3}$, \\ Christoph Schankin ${ }^{3}$ and Rüdiger von Kries'
}

\begin{abstract}
Introduction: Stress is considered the major contributor to migraine and tension-type headache in adolescents. Previous studies have focused on general stressors, whereas the aim of the present study was to investigate associations between individuals' stressful experiences and different types of headache.

Methods: Adolescents from I0th and I I th grades of grammar schools filled in questionnaires. Stressful experiences were measured with the Trier Inventory of Chronic Stress. Type of headache was classified according to the International Classification of Headache Disorders. Linear regressions, adjusted for sex and grade, were calculated to estimate differences in stress scores that can be attributed to migraine, tension-type headache or miscellaneous headache.

Results: A total of 1260 questionnaires were analysed. Tension-type headache, migraine and co-existing migraine plus tension-type headache were found in $48.7 \%, 10.2 \%$ and $19.8 \%$ of the participants. In subjects with migraine or co-existing migraine plus tension-type headache, high increases in stress scores were found in all investigated dimensions, whereas much weaker and inconsistent associations were found in subjects with tension-type headache only.

Conclusions: The characteristic of migraine is more associated with stressful experiences than this is the case for tensiontype headache. This suggests that adolescent migraine patients might especially benefit from behavioural interventions regarding stress.
\end{abstract}

\section{Keywords}

Stress, TICS, headache, migraine, tension-type headache

\section{Abbreviations}

TTH, tension-type headache; TICS, Trier Inventory of Chronic Stress; ICHD, International Classification of Headache Disorders, 2nd edition; $\mathrm{MH}$, miscellaneous headache

Date received: 2I May 2010; revised: 25 August 2010; accepted: 6 September 2010

\section{Introduction}

Migraine and tension-type headache (TTH) are the most frequently reported types of primary headache among adolescents, with prevalences of approximately $10 \%$ for migraine and $15-20 \%$ for TTH in populationbased studies (1-4).

Chronic stress, the prolonged imbalance between situational requirements and the individual's coping resources, has been repeatedly found to be related with headaches in adolescents (5-12). Associations with exposure to stressors in adolescents have been reported for both migraine and TTH. It was found that children and adolescents with migraine had more days absent from school $(6,7,13,14)$.

\footnotetext{
'Ludwig-Maximilians-University, Germany.

${ }^{2}$ Dr von Hauner's Children Hospital, Germany.

${ }^{3}$ Klinikum Grosshadern, Germany.

Corresponding author:

Astrid Milde-Busch, Institute of Social Paediatrics and Adolescent Medicine, Ludwig-Maximilians-University Munich, Heiglhofstrasse 63, 81377 Munich, Germany

Email: Astrid.Milde-Busch@med.uni-muenchen.de
} 
Furthermore, migraine attacks were found to be correlated with the amount of homework or with the timing of examinations $(6,15)$. Other studies showed that TTH in adolescents seems to be associated with social stress: adolescents with TTH had fewer peers, were more frequently exposed to conflicts within their families and their parents were more likely to be divorced $(13,16)$.

However, in previous studies, the effects of situations which are generally considered stressful, rather than the individual's appraisal of stressors or their individual coping abilities, have been investigated in relation to headache $(6-8,13,15-17)$. Most of these studies focused on stressors by asking open-ended questions about life events and situations that are generally considered to be related to stress. Other recent studies evaluated perceived stress by asking for the frequency of 'feeling stressed' or by implementing visual analogue scales that should represent the current level of stress, but without differentiation between the origin of the stressors (10-12). In contrast, the Trier Inventory of Chronic Stress (TICS) is an instrument which allows the assessment of the individual's appraisal of potentially stressful situations (18).

The objective of the present investigation was to identify possible associations between perceived stress, as measured with the TICS, and headache in adolescents. In addition, we aimed to assess whether there are differences between adolescents with migraine and TTH. In detail, we expected to find larger increases in TICS scores for adolescents with migraine than for adolescents with TTH. Furthermore, students with migraine were supposed to have higher stress scores on dimensions representing high demands, while students with TTH were expected to show higher scores in social stress dimensions.

Additionally, we aimed to investigate associations between 'objective' exposure to stress, assessed as, for example, the amount of time for recreation and social resources, and prevalent headaches.

\section{Subjects and Methods}

\section{Study population}

The present study was approved by the Data Safety Officer and the Ethic Committee (082-08) of the Medical Faculty of the Ludwig-MaximilansUniversity Munich and the Bavarian Ministry for Teaching and Culture. Written informed consent was obtained from participants' parents.

The present study is a cross-sectional study in 10th and 11th grade students in public grammar schools in Munich, southern Germany.

\section{Study design and procedure}

The acquisition phase of the schools for the present study started in August 2008 and was completed in October 2008. The principals of all 37 public grammar schools in Munich received a letter describing the study, together with a supporting letter from the Bavarian Ministry for Teaching and Culture. Principals of 11 grammar schools declared consent to participate in data collection. They were asked to name a contact person at their schools and to provide some data on their school, such as the number of classes, number of students, specialisation of the schools (classical languages, modern languages, humanistic, natural sciences, social sciences, fine arts, economics; multiple specialisations were possible) and region (central vs outer Munich regions). Non-participating schools were asked to provide these data as well. In the case of non-responding schools, the respective information was retrieved from their internet homepages. The contact person (usually a teacher or school psychologist) received a package consisting of further information about the study for teachers and the families of the potential participants. Contact persons distributed this material consisting of information about the study, separately for the students and their parents, and a consent form to all students of the 10th and 11th grades in their schools. As most students were younger than 18 years, their parents were asked to fill in this form to give written consent that their child was allowed to participate in the study. Contact persons collected these consent forms and stored them at school. For data safety, study members did not obtain individual information on adolescents' names or addresses nor did they receive the informed consent forms.

The field phase of data collection started in October 2008 and was completed in February 2009. On the day of data collection, contact persons or class teachers identified those adolescents whose parents had given written consent. Those subjects were given a questionnaire and asked to complete it immediately during a regular school hour in class. It took about $25-35 \mathrm{~min}$ to complete the questionnaire. Questionnaires were numbered consecutively. Upon request in some schools after the questionnaires had been obtained, an informational lecture about headache was given by one of the study members, in appreciation for the students' participation in this study.

\section{Instruments}

Stressful experiences were assessed with the TICS, a 57-item self-report instrument yielding the following nine dimensions extracted by factor analysis (18). The dimensions school overload, social overload and 
pressure to succeed refer to stress due to high demands. The dimensions dissatisfaction with job, excessive school demands, lack of social recognition, social tension and social isolation refer to stress due to lack of need satisfaction. Furthermore, the TICS contains a dimension on chronic worries as a personality trait. Instead of an additive score over all dimensions, in the test manual the authors of the TICS suggest using the chronic stress screening scale as a global measure for chronic stress experience, consisting of 12 items taken from the other dimensions.

Zero up to three missing values per dimension can be accepted. For each item, the frequency of personal experience within the past 3 months had to be indicated on a 5-point Likert scale from 0 (never) to 4 (very often). Item examples are: 'I have to deal too much with problems of other persons' (item 28; dimension social overload) or 'I have to carry out work where I hardly can apply my abilities' (item 48; dimension dissatisfaction with job). Individual mean scores for each dimension were calculated and then linearly transformed to age-group related $\mathrm{T}$ norm values $($ mean $=50 ; \mathrm{SD}=10) \quad(18)$. Higher $\mathrm{T}$ values correspond to more stress on the respective dimension. For the individual $\mathrm{T}$ value, it was determined whether this was within the normal range of the $\mathrm{T}$ distribution, below or above average. The TICS had been psychometrically tested with subjects between 16-70 years and good internal consistency and convergent and discriminant validity were obtained (18). It was expected that some of the students would earn own money. Therefore, before the beginning of this study, the authors of the TICS had been contacted; they confirmed the appropriateness of this instrument for the intended study. The authors of the TICS recommended to instruct students explicitly to apply work-related items to school and homework, but to refrain from re-phrasing items. We explicitly instructed the students that the job questions pertain to their school demands.

As proxies for exposure to stressors, the following items were assessed: an open-ended question inquired self-rated sources of headaches. Daily hours of leisure time $(<1,1-3,3-5,>5 \mathrm{~h})$ and whether this amount of time was rated as sufficient for recreation (yes, no) was asked. Two further questions on social resources asked whether the student has a best friend (yes, no) and intimate friend (this means a boyfriend or girlfriend; yes, no), respectively. Furthermore, principals of schools were asked to determine the number of students within the respective classes.

Items on headaches were taken from a validated questionnaire (3) which was based on the German translation of International Classification of Headache Disorders, 2nd edition (ICHD) (19).
A positive answer to the screening question 'Did you have headache during the last six months?' identified adolescents with or without headache. Subjects with any headache answered further questions regarding frequency, duration, characteristics and symptoms of their headaches. Severity of headache was estimated with a 10-point visual analogue scale from grade 1 (very low) to grade 10 (very high). Severity was considered mild, moderate and high when subjects indicated $1-3,4-6$, or $7-10$, respectively. To gauge treatment of headache, the frequency of medication used during the last 3 months and the type of medication (i.e. generic as well as trademark) used were asked.

Any type of migraine and any type of TTH were classified according to the ICHD criteria as primary headache disorders (19). The classifications of migraine included the subtypes migraine (with or without aura, corresponding to ICHD codes 1.1 and 1.2 , respectively), chronic migraine (ICHD code 1.5.1), probable migraine (ICHD codes 1.6.1 and 1.6.2) and probable chronic migraine (ICHD code 1.6.5), with a minimum of five headache episodes. The classification of TTH included the subtypes infrequent episodic TTH, frequent episodic TTH, chronic TTH, probable infrequent episodic TTH, probable frequent episodic TTH and probable chronic TTH (corresponding to ICHD codes $2.1,2.2,2.3,2.4 .1,2.4 .2$ and 2.4.3, respectively). Co-existing migraine and TTH ('migraine plus TTH') could be classified in subjects fulfilling the criteria for both probable (chronic) migraine and probable (episodic or chronic) TTH, which require matching with all but one of the respective criteria for migraine or TTH. All other subjects with headache that did not match any of these classifications for primary headache were considered to have miscellaneous headache $(\mathrm{MH})$.

Further questions pertained to sex (male, female), grade (10th, 11th) and socio-economic variables: Monthly amount of pocket money was dichotomized '50 Euro or less' versus 'more than 50 Euro'. Adolescents' own income was graded as 'any' or 'nothing'. Questions on parents' employment status were taken from the German Health Interview and Examination Survey for Children and Adolescents and considered 'full time' if indicated as such, and otherwise as 'not full-time' (20).

\section{Statistical analysis}

Associations between dichotomous variables were tested by using chi-square statistics. Mean and SD of the T values of the TICS were reported. Multiple linear regression models with adjustment for sex and grade as confounding co-variables were used to quantify the difference of the TICS scores between adolescents with and without headache. Separate linear regression 
models for any headache, migraine, TTH, co-existing migraine plus TTH and MH (each comparing against 'no headache') as predictors were calculated. Differences in polytomous variables (this means the number of students in class and daily leisure time) between students without headache and those with prevalent headache were tested by using CochraneArmitage tests for trend for ordered categories. Multiple logistic regression models adjusted for sex and grade were used to estimate associations between dichotomous measures of stress as exposures and prevalent headache as outcome. To estimate associations between the polytomous variable leisure time as exposure and prevalent headache as outcome, leisure time was dummy coded using $>5 \mathrm{~h}$ daily leisure time as reference category in further multiple logistic regression models. Separate logistic regression models for any headache, migraine, TTH, co-existing migraine plus TTH and MH (each comparing against 'no headache') were calculated. Odds ratios (OR) and 95\% confidence intervals $(\mathrm{CI})$ were reported. $P$-values $<0.05$ were considered to indicate a significant difference. To account for multiple testing of the TICS dimensions, Bonferroni correction was applied, separately for each dimension of the TICS $(0.05 / 10=0.005)$. The evaluations were performed with the SAS software package (v9.2; SAS Institute Inc. Cary, NC, USA).

\section{Results}

\section{Participating schools}

Schools whose principal declared consent with data collection for the study did not differ significantly from non-participating schools in terms of number of students in school, number of students in 10th and 11th grades, number of 10th and 11th grades, specialisation of schools and region (data not shown).

\section{Participants}

A total of 1818 adolescents were invited for participation by their contact persons. At the respective day of data collection, $1504(82.7 \%)$ were present at school. Reasons for absence from school were suffering from seasonal infectious diseases or participation in outof-school activities. Of all present individuals, 1426 $(94.8 \%)$ actually filled in the questionnaire. One hundred sixty-six questionnaires $(11.6 \%)$ had to be excluded from analysis because of missing values in relevant socio-economic variables, leaving a total of 1260 analyzable questionnaires. Subjects with excluded questionnaires did not differ significantly from the remaining subjects with respect to prevalent headache and stress (data not shown).
Six hundred sixty-nine $(53 \%)$ of the participants were female, $591(47 \%)$ were male. Six hundred fiftyone $(52 \%)$ of the students were visiting the 10 th grade, $609(48 \%)$ the 11th grades, mean age was $16.2 \pm 0.9$ years. One thousand and three $(80 \%)$ of the adolescents reported to receive 50 Euro or less as pocket money per month, 698 (55\%) reported to earn own money. Fathers of $1145(91 \%)$ and mothers of $474(38 \%)$ students were full-time employed.

\section{Prevalence of headache}

Table 1 shows the detailed distribution of headaches in the study population. Of all participants, 83.1\% reported to suffer from any headache at least once during the last 6 months. Migraine only was reported by 129 subjects $(10.2 \%)$. TTH only was reported by 614 participants $(48.7 \%)$. Co-existing migraine plus TTH were found in 249 subjects $(19.8 \%)$ ). A further 55 subjects $(4.4 \%)$ reported experiencing other headaches (MH).

\section{Characteristics of the study population}

The distribution of socio-economic variables for students with or without headache is presented in Table 2. Significantly more girls were found in the group of subjects suffering from headaches compared to the group without headache $(56.4 \%$ vs $37.1 \%$; chi-squared $=26.4 ; \quad P<0.0001) . \quad$ No $\quad$ significant

Table I. Six-month prevalence of migraine, tension-type headache $(\mathrm{TTH})$ and miscellaneous headache $(\mathrm{MH})$

\begin{tabular}{lrr}
\hline & $n$ & $\%$ \\
\hline No headache & 213 & 16.9 \\
Migraine (total) & 129 & 10.2 \\
Of which migraine & 25 & 2.0 \\
Of which chronic migraine & 1 & 0.1 \\
Of which probable migraine & 102 & 8.1 \\
Of which probable chronic migraine & 1 & 0.1 \\
TTH (total) & 614 & 48.7 \\
Of which infrequent episodic TTH & 50 & 4.0 \\
Of which frequent episodic TTH & 75 & 6.0 \\
Of which chronic TTH & 163 & 12.9 \\
Of which probable infrequent episodic TTH & 108 & 8.6 \\
Of which probable frequent episodic TTH & 101 & 8.0 \\
Of which probable chronic TTH & 117 & 9.3 \\
Co-existing migraine plus TTH & 249 & 19.8 \\
Any MH & 55 & 4.4 \\
Total study population & 1260 & 100.0 \\
\hline
\end{tabular}

TTH, tension-type headache; $\mathrm{MH}$, miscellaneous headache. 
differences between subjects reporting headache and subjects without headache were found with respect to all other socio-economic variables.

\section{Stressful experiences}

Table 2 further shows the proportion of subjects with normal or below-average versus above-average
$\mathrm{T}$ values of all TICS dimensions amongst students with or without headache. After applying Bonferroni correction, there were statistically significantly more subjects experiencing excessive school demands, lack of social recognition or chronic worries among those reporting headache, also accounting for higher values on the chronic stress screening scale.

Table 2. Distribution of selected socio-economic characteristics and proportion of normal/below-average and above-average $\mathrm{T}$ values for all TICS dimensions in subjects with and without headache

\begin{tabular}{|c|c|c|c|c|c|}
\hline \multirow[b]{2}{*}{ Characteristic } & & \multicolumn{2}{|c|}{ Any headache $(n=1047)$} & \multicolumn{2}{|c|}{ No headache $(n=2 \mid 3)$} \\
\hline & & $n$ & $\%$ & $n$ & $\%$ \\
\hline \multirow[t]{2}{*}{ Sex ${ }^{c}$} & Male & 457 & 43.6 & 134 & 62.9 \\
\hline & Female & 590 & 56.4 & 79 & 37.1 \\
\hline \multirow[t]{2}{*}{ Grade } & l0th & 535 & 51.1 & 116 & 54.5 \\
\hline & IIth & 512 & 48.9 & 97 & 45.5 \\
\hline \multirow[t]{2}{*}{ Pocket money per month } & $\leq € 50$ & 829 & 79.2 & 174 & 82.7 \\
\hline & $>€ 50$ & 218 & 20.8 & 39 & 18.3 \\
\hline \multirow[t]{2}{*}{ Own income } & Nothing & 457 & 43.6 & 105 & 49.3 \\
\hline & Any & 590 & 56.4 & 108 & 50.7 \\
\hline \multirow[t]{2}{*}{ Father's employment } & Full-time & 949 & 90.6 & 196 & 92.0 \\
\hline & Not full-time & 98 & 9.4 & 17 & 8.0 \\
\hline \multirow[t]{2}{*}{ Mother's employment } & Full-time & 398 & 38.0 & 76 & 35.7 \\
\hline & Not full-time & 649 & 62.0 & 137 & 64.3 \\
\hline \multicolumn{6}{|l|}{ TICS dimensions } \\
\hline \multirow[t]{2}{*}{ School overload ${ }^{\mathrm{a}}$} & Normal/below & 798 & 76.2 & 179 & 84.0 \\
\hline & Above average & 249 & 23.8 & 34 & 16.0 \\
\hline \multirow[t]{2}{*}{ Social overload } & Normal/below & 977 & 93.3 & 200 & 93.9 \\
\hline & Above average & 70 & 6.7 & 13 & 6.1 \\
\hline \multirow[t]{2}{*}{ Pressure to succeed } & Normal/below & 1019 & 97.3 & 208 & 97.7 \\
\hline & Above average & 28 & 2.7 & 5 & 2.3 \\
\hline \multirow[t]{2}{*}{ Dissatisfaction with job ${ }^{\mathrm{a}}$} & Normal/below & 763 & 72.9 & 171 & 80.3 \\
\hline & Above average & 284 & 27.1 & 42 & 19.7 \\
\hline \multirow[t]{2}{*}{ Excessive school demands ${ }^{c}$} & Normal/below & 539 & 51.5 & 149 & 70.0 \\
\hline & Above average & 508 & 48.5 & 64 & 30.0 \\
\hline \multirow[t]{2}{*}{ Lack of social recognition ${ }^{c}$} & Normal/below & 776 & 74.1 & 184 & 86.4 \\
\hline & Above average & 271 & 25.9 & 29 & 13.6 \\
\hline \multirow[t]{2}{*}{ Social tension } & Normal/below & 802 & 76.6 & 170 & 79.8 \\
\hline & Above average & 245 & 23.4 & 43 & 20.2 \\
\hline \multirow[t]{2}{*}{ Social isolation ${ }^{\mathrm{a}}$} & Normal/below & 899 & 85.9 & 196 & 92.0 \\
\hline & Above average & 148 & 14.1 & 17 & 8.0 \\
\hline \multirow[t]{2}{*}{ Chronic worries $^{\mathrm{b}}$} & Normal/below & 813 & 77.7 & 186 & 87.3 \\
\hline & Above average & 234 & 22.3 & 27 & 12.7 \\
\hline \multirow[t]{2}{*}{ Chronic stress screening scale $^{c}$} & Normal/below & 811 & 77.5 & 192 & 90.1 \\
\hline & Above average & 236 & 22.5 & 21 & 9.9 \\
\hline
\end{tabular}

Significant $P$ values of chi-square tests: ${ }^{\mathrm{a}} P<0.05 ;{ }^{\mathrm{b}} P<0.005 ;{ }^{\mathrm{c}} P<0.00$ I.

TICS, Trier Inventory of Chronic Stress. 


\section{Associations between stressful experiences and headache}

Mean and SD of the T values for all TICS dimensions are presented in Table 3, separately for subjects without headache, for subjects with any headache and separately for type of headache. Table 4 shows the respective beta coefficients of the multiple linear regression models, these represent the adjusted differences in $T$ values which can be attributed to prevalent headache. Prevalent headache was associated with an increase in experienced stress in the dimensions school overload, dissatisfaction with job, excessive school demands, lack of social recognition and social isolation in the range of 1.9 to $3.4 \mathrm{~T}$ norm points, also accounting for an increase in chronic worries $(3.1$ points; $P<0.001)$ and on the chronic stress screening scale ( 3.5 points; $P<0.001)$.

Considerable differences in affected stress dimensions were observed between types of headache. Subjects suffering from migraine reported significantly higher $\mathrm{T}$ values for all TICS dimensions in the range of 3.3 to 7.3 points, corresponding to 7.3 points regarding chronic worries $(P<0.001)$ and 7.7 points on the chronic stress screening scale $(P<0.001)$. For subjects with migraine plus TTH, higher $\mathrm{T}$ values in all stress dimensions were also observed, but with lower scores than subjects with pure migraine. After Bonferroni correction, the dimension social overload failed to reach the level of statistical significance. For subjects with TTH only, increased T values were found for dissatisfaction with job and excessive school demands. After Bonferroni correction, the dimensions lack of social recognition and chronic worries as well as the chronic stress screening scale can no longer be regarded as statistically significant for adolescents with TTH. For subjects with $\mathrm{MH}, \mathrm{T}$ values did not differ significantly from subjects without headache.

\section{External measures of stress}

A general exposure to stress was reported by students with migraine $(\mathrm{OR}=2.1$; 95\% CI 1.3-3.4), TTH (1.9; $1.3-2.7)$ and co-existing migraine plus TTH $(3.2 ; 2.1-$ 4.8). Only for subjects with co-existing migraine plus TTH, there was a significant association with increasing number of students in the class found $(P=0.02)$. Students with migraine reported generally fewer hours of daily leisure time $(P=0.04)$, but separate adjusted comparisons did not reveal any individual statistically significant effect. Subjects with migraine and co-existing migraine plus TTH were more likely to report that the amount of daily leisure time was not sufficient for recreation $(\mathrm{OR}=2.3 ; 95 \%$ CI $1.4-3.7$ and $\mathrm{OR}=1.8 ; 95 \%$ CI 1.2-2.7, respectively). No differences in the

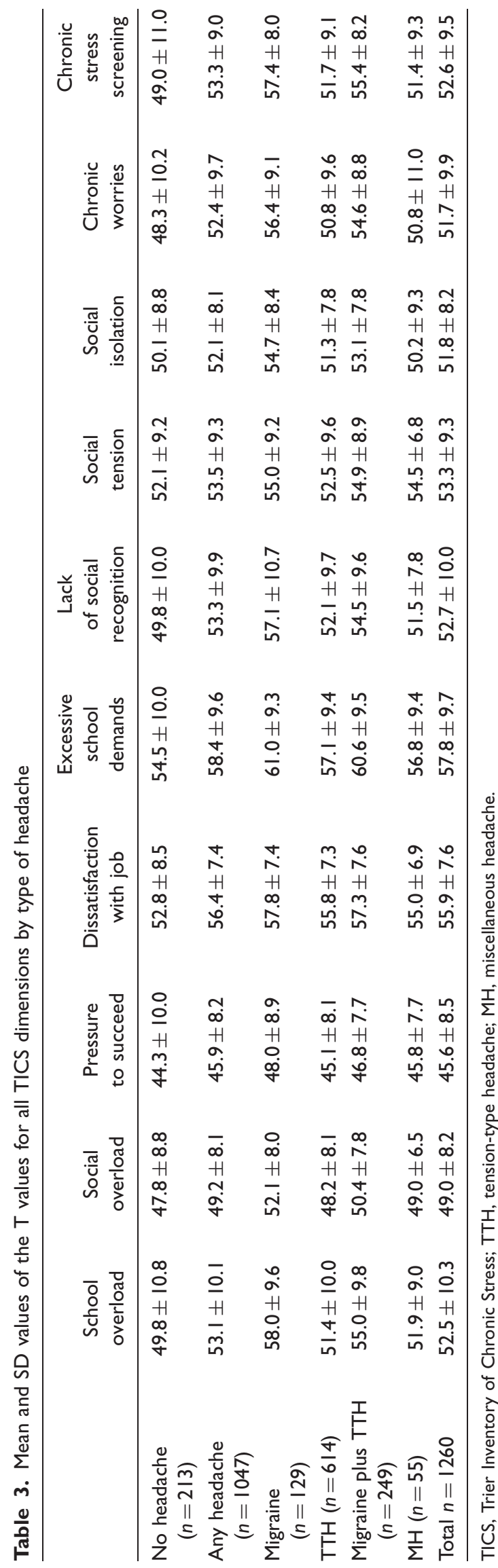


availability of a best friend or an intimate friend were found (Table 5).

\section{Discussion}

The TICS instrument allows the discrimination of stressful experiences according to whether they originate from high demands (when subjects feel overburdened by too many or too challenging tasks and by too many social engagements) or dissatisfaction with life situation (when subjects feel unsatisfied by non-interesting work, overburdened by too complicated tasks, do not feel adequately acknowledged for their efforts, often get into social conflicts and often feel alone). Compared to subjects without headache, higher stress scores were found for all investigated dimensions in subjects with migraine and co-existing migraine plus TTH, whereas in subjects with TTH increased stress scores were confined to only few contexts.

In adolescents with migraine or co-existing migraine plus TTH, a considerable shift towards higher stress scores was observed in all dimensions, indicating that subjects with migraine perceive stress not only because of high perceived demands, but also with respect to their need satisfaction. Additionally, chronic worries as indicators of a personality trait were increased. Although the same dimensions were affected, the strength of the effect was considerably lower in students with co-existing migraine plus TTH than in students with migraine only. Therefore, it might be possible that subjects with co-existing migraine plus TTH have slightly better appraisal and coping strategies than subjects with pure migraine, resulting only in occasional headache attacks without showing the full picture of a migraine episode (21). Previous studies focusing only on stressors without accounting for individual appraisal and coping abilities reported same or even more stress in adolescents with co-existing migraine plus TTH than in subjects with migraine only $(7,22)$. Taken together, the present findings of similar stressful experiences in subjects with migraine and co-existing migraine plus TTH can be discussed in the line that TTH episodes in the latter subjects might reflect milder migraine attacks and not really a TTH. It, therefore, seems reasonable to conclude that migraine attacks are the predominant disorders in these subjects.

The neurobiological mechanisms through which stressors might trigger the cascade of migraine attacks and the development of chronic migraine are unclear, but are likely to be linked to neurochemical changes related to the patients' physiological response to stress (23). Neurophysiological studies in migraine disclose an abnormality of cortical excitability and information processing in patients with migraine between attacks. Lack of habituation is the principal and most 
Table 5. Prevalences of external stressors and associations with types of headache in comparison with no headache

\begin{tabular}{|c|c|c|c|c|c|c|}
\hline & $\begin{array}{l}\text { No headache } \\
\quad(n=213)\end{array}$ & $\begin{array}{l}\text { Any headache } \\
\quad(n=1047)\end{array}$ & $\begin{array}{l}\text { Migraine } \\
(n=129)\end{array}$ & $\begin{array}{c}\text { TTH } \\
(n=6 \mid 4)\end{array}$ & $\begin{array}{l}\text { Migraine }+ \text { TTH } \\
\quad(n=249)\end{array}$ & $\begin{array}{c}\mathrm{MH} \\
(n=55)\end{array}$ \\
\hline \multicolumn{7}{|l|}{ 'Stress' as a source } \\
\hline $\mathrm{No}^{\mathrm{a}}$ & $73.2 \%$ & $52.4 \%$ & $51.9 \%$ & $56.2 \%$ & $41.4 \%$ & $61.8 \%$ \\
\hline Yes & $26.8 \%$ & $47.6 \%$ & $48.1 \%$ & $43.8 \%$ & $58.6 \%$ & $38.2 \%$ \\
\hline$P$ raw $^{\mathrm{b}}$ & & $<0.0001$ & $<0.0001$ & $<0.0001$ & $<0.0001$ & 0.10 \\
\hline OR $(95 \% \mathrm{Cl})^{*}$ & & $2.1(1.5-3.0)$ & $2.1(1.3-3.4)$ & $1.9(1.3-2.7)$ & $3.2(2.1-4.8)$ & $1.4(0.8-2.8)$ \\
\hline \multicolumn{7}{|l|}{ Students in class } \\
\hline$P$ raw $^{c}$ & & 0.25 & 0.87 & $0.4 I$ & 0.01 & 0.48 \\
\hline$P$ adjusted & & 0.10 & 0.23 & 0.71 & 0.02 & 0.50 \\
\hline \multicolumn{7}{|l|}{ Leisure time } \\
\hline$>5 \mathrm{~h}$ per day ${ }^{\mathrm{a}}$ & $21.5 \%$ & $20.3 \%$ & $16.7 \%$ & $22.4 \%$ & $15.7 \%$ & $25.5 \%$ \\
\hline OR $(95 \% \mathrm{Cl})^{*}$ & & I & I & I & I & I \\
\hline $3-5 \mathrm{~h}$ per day & $34.9 \%$ & $39.4 \%$ & $31.0 \%$ & $41.6 \%$ & $37.1 \%$ & $45.5 \%$ \\
\hline OR $(95 \% \mathrm{Cl})^{*}$ & & $1.0(0.7-1.6)$ & $1.0(0.5-2.0)$ & $1.0(0.7-1.6)$ & $1.2(0.7-2.1)$ & $1.0(0.5-2.2)$ \\
\hline $\mathrm{I}-3 \mathrm{~h}$ per day & $30.1 \%$ & $28.7 \%$ & $30.2 \%$ & $25.7 \%$ & $37.5 \%$ & $18.2 \%$ \\
\hline OR $(95 \% \mathrm{Cl})^{*}$ & & $0.8(0.5-1.2)$ & $0.9(0.5-1.8)$ & $0.6(0.4-1.0)$ & $1.2(0.7-2.1)$ & $0.4(0.1-I .0)$ \\
\hline$<\mathrm{I} \mathrm{h}$ per day & $13.4 \%$ & $11.6 \%$ & $22.2 \%$ & $10.2 \%$ & $9.7 \%$ & $10.9 \%$ \\
\hline OR $(95 \% \mathrm{Cl})^{*}$ & & $0.7(0.4-1.2)$ & $1.7(0.8-3.6)$ & $0.6(0.3-1.1)$ & $0.7(0.4-1.5)$ & $0.5(0.2-1.6)$ \\
\hline$P \operatorname{raw}^{c}$ & & 0.59 & 0.04 & 0.12 & 0.50 & 0.15 \\
\hline \multicolumn{7}{|l|}{ Recreation } \\
\hline$Y_{e s}^{a}$ & $55.6 \%$ & $46.4 \%$ & $32.5 \%$ & $52.7 \%$ & $37.1 \%$ & $50.0 \%$ \\
\hline No & $44.4 \%$ & $53.6 \%$ & $67.5 \%$ & $47.3 \%$ & $62.9 \%$ & $50.0 \%$ \\
\hline$P$ raw $^{\mathrm{b}}$ & & 0.02 & $<0.0001$ & 0.47 & $<0.0001$ & 0.47 \\
\hline OR $(95 \% \mathrm{Cl})^{*}$ & & $1.3(0.9-1.8)$ & $2.3(1.4-3.7)$ & $1.0(0.7-1.4)$ & $1.8(1.2-2.7)$ & I.I (0.6-2.0) \\
\hline \multicolumn{7}{|l|}{ Best friend } \\
\hline$Y_{e s}{ }^{a}$ & $86.3 \%$ & $85.6 \%$ & $86.8 \%$ & $84.9 \%$ & $86.6 \%$ & $86.8 \%$ \\
\hline No & $13.7 \%$ & $14.4 \%$ & $13.2 \%$ & $15.1 \%$ & $13.4 \%$ & $13.2 \%$ \\
\hline$P$ raw $^{\mathrm{b}}$ & & 0.82 & 0.88 & 0.63 & 0.92 & 0.92 \\
\hline OR $(95 \% \mathrm{Cl})^{*}$ & & I.I (0.7-I.7) & $1.0(0.5-1.9)$ & I.I (0.7-I.8) & $0.9(0.5-1.6)$ & $0.9(0.4-2.2)$ \\
\hline \multicolumn{7}{|l|}{ Boyfriend/girlfriend } \\
\hline Yes $^{\mathrm{a}}$ & $23.0 \%$ & $25.2 \%$ & $32.0 \%$ & $22.0 \%$ & $31.0 \%$ & $18.2 \%$ \\
\hline No & $77.0 \%$ & $74.8 \%$ & $68.0 \%$ & $78.0 \%$ & $69.0 \%$ & $81.8 \%$ \\
\hline$P$ raw $^{\mathrm{b}}$ & & 0.50 & 0.07 & 0.78 & 0.05 & 0.45 \\
\hline OR $(95 \% \mathrm{Cl})^{*}$ & & $\mathrm{I} .0(0.7-1.4)$ & $0.7(0.4-1.2)$ & I.I (0.8-I.6) & $0.7(0.5-1.1)$ & $\mathrm{I} .4(0.7-3.0)$ \\
\hline
\end{tabular}

${ }^{\text {a}}$ Reference category for the logistic regression model.

${ }^{\mathrm{b}} P$-value of chi-square test.

${ }^{c} P$-value of Cochrane-Armitage test for trend.

Adjusted for sex and grade.

TTH, tension-type headache; $\mathrm{MH}$, miscellaneous headache; $\mathrm{OR}$, odds ratio; $\mathrm{Cl}$, confidence interval.

reproducible interictal abnormality in sensory processing in these patients. Cortical habituation is seen as a protective mechanism against overstimulation or physiological stress. It is conceivable that stress could produce additional chemical changes in the cerebral cortex of sufficient degree to promote migraine attacks (24). One study has shown increased neurophysiological and autonomic reactivity in patients with migraine before a migraine attack (25). It is not yet clear if stress increases cortical excitability due to adrenergic mechanisms, and if the reduction of this adrenergic input due to the better coping strategies is one cause of the observed differences. The prophylactic effect of $\beta$-blockers on migraine can partly be explained by the reduction of the adrenergic effect on cortical excitability (26).

Stressful experiences in subjects with TTH were smaller in effect size than in subjects with migraine and pertain to few dimensions on lack of need satisfaction dimensions, namely dissatisfaction with job and excessive school demands. Previous studies reported 
associations between TTH and exposure to stressors $(7,13)$, which could be reflected in the high demands dimensions in our study. In our study, none of the corresponding dimensions were affected. Only a few of the previous studies were population-based $(6,7)$ and most included children and adolescents $(7,8,16)$, whereas our subjects were all adolescents, which might account for substantial differences between these findings. Further, it has to be noted that the prevalence of TTH in our study was considerably higher than in other studies. To assess whether the failure to detect further or stronger associations between stress and TTH might be caused by possible dilution of the effects by over-diagnosis of 'probable' or 'infrequent' TTH subtypes, stratified analyses for adolescents with episodic or chronic TTH versus probable episodic or probable chronic TTH were performed. No meaningful differences, however, were observed (data not shown). If post-hoc analyses were stratified for chronic, frequent and infrequent episodic TTH, it was found that the number of affected stress dimensions decreased with decreasing frequency of TTH episodes: subjects with infrequent episodic TTH did not report higher stress on any dimension. For subjects classified as chronic TTH cases, there was also no significant association with any of the high demands dimensions observed (data not shown). Therefore, the failure to detect associations between stress and TTH is unlikely to be explained only by dilution of TTH classifications. The association with some stressors found in some previously published studies might also reflect different measures: these measures might not necessarily indicate perceived stress due to high demands, but rather exposure to environmental conditions presumed to account for stress. For example, the number of students in the class might be a marker of social stress, but does not allow drawing conclusions regarding the individual's experience of social tension.

Analyses of external measures of exposures to stress and social support revealed only few differences between subjects with any types of headaches and headache-free students. This finding might point to a higher sensitivity of the TICS or comparable measures of individual experiences and burden of stress. However, both types of measures, TICS and 'objective' measures of stress emphasize the stronger associations between stress and migraine, rather than between stress and TTH.

At this point, it can only be speculated why there are such large differences between the stress scores in migraineurs and TTH sufferers. One hypothesis is that subjects who complain about TTH might have better coping strategies for stress, which might protect them from developing a central hyper-excitability. Another hypothesis is that subjects with $\mathrm{TTH}$ are more likely to develop muscular tenderness as a reaction to stress (27), but are less vulnerable to psychological stress, for example from anxiety or depression (28-30).

The time course, whether stress precedes headache onset or whether headache episodes are to be considered as stressful events, is still under debate (31). Nash and colleagues $(32,33)$ postulated multiple connections on how stress and headache can be inter-related: stress can contribute to the onset or expression of headache in vulnerable persons $(22,34)$, can trigger individual headache episodes (35-42), can exacerbate the progression of a headache disorder from an episodic to a chronic condition (43-45) and can independently worsen headache-related disability and quality of life in headache sufferers (31,46). Furthermore, headache episodes themselves can serve as stressors $(17,47)$, that impact an individual's health and well-being. Since our data are cross-sectional, we are only reporting associations and do not claim causal relations.

\section{Study strengths and limitations}

The major strength of our study is its school-based, not hospital-based, data collection, although recruitment was confined to a subgroup of students visiting a grammar school. Participating schools did not differ from schools which refused to participate. Given the high participation rate $(94.8 \%)$ and the comparatively low number of excluded questionnaires $(11.6 \%)$, sampling bias seems to be unlikely. Unlike other previous reports, the analysis was adjusted for relevant confounding variables that were shown to be associated with prevalence of headache and with stress. Thus, we could estimate the difference in stress score that are, indeed, associated with prevalent headache.

Previous studies on the association between adolescent migraine and stress have focused on the demand side $(6,7,13,15,17,22)$. This study adds the investigation of the individual appraisal of stressful situations. While other studies mostly assessed stressors such as the number of days absent from school, in the present study the individual perception of a burden from demands and lack of need satisfaction is investigated. Even though the TICS is a comparatively new instrument, it has already been applied in a number of other studies $(23,48-51)$.

There are some weaknesses of the present study. Classifications of types of headache were not validated by physicians' diagnoses, but were based on a selfadministered questionnaire. However, a number of studies found reasonable sensitivity, specificity and predictive values for headache screening questionnaires for children and adolescents (52-54). Construction of the headache questionnaire was based on the criteria of the ICHD (19). and was similar to widely used 
questionnaires which were already administered in population-based cross-sectional studies on adolescents $(3,55)$. However, a possible overdiagnosis of headaches, especially of TTH, cannot be ruled out.

Although the TICS is psychometrically validated for subjects between 16-70 years, no additional papers using the TICS in an adolescent sample had been published up to now. Approximately one-quarter of the students of the present sample was slightly (maximally one year) younger than 16 years, but there is no reason to believe that these subjects might not have been able to answer some items correspondingly. Indeed, we did not find any association between test performance and age below 16 years in our data (data not shown). While general statements regarding test profiles are only valid within the age ranges used for the standardisation of the instrument, relative comparisons, as performed in our study, are likely to be valid if the test is applied to individuals at an age very close to the margins of the age range used for standardisation.

The clinical relevance of the observed statistically significant associations between headache and perceived stress might be questionable, especially since elevated stress scores even for students with migraine were lower than the clinically relevant difference of $10 \mathrm{~T}$ norm points. However, in epidemiological studies with population-based or healthy samples, such large differences as in individual medicine cannot always be obtained. Epidemiological methodology does not require that necessarily all migraineurs experience elevated stress.

It is known that students visiting a grammar school in Germany are more likely to experience headache than students of other school types (3). The higher prevalence of headache contrasts with the reported higher quality of life and fewer psychosomatic health complaints in students visiting grammar schools compared to other schools (56). The proportion of subjects with headache in this study, confined to a municipal student population in a city where an abundance of wealth for a high proportion of students might be equally stressful as the perceived lack in those who do not have that affluent parents, was even higher than in other studies using the same screening instrument $(3,55)$. This might raise concerns regarding external validity. The main lessons from this study, however, pertain to the differences between migraine and TTH rather than the absolute prevalence of either.

\section{Conclusions}

The present systematic investigation of individual experience of stress and headache in adolescents revealed considerable differences between subjects with migraine and subjects with TTH. These differences might reflect different biological mechanisms. Migraine patients might, therefore, be more likely to benefit from behavioural interventions to improve stress appraisal and coping strategies for treatment and prevention than TTH patients.

\section{Acknowledgements}

The authors would like to thank Michaela Bonfert, Kristina $\mathrm{Hu} ß$ and Petra Sostak for their support in data collection and for giving lessons regarding headache in the participating schools. We thank all participants for their time and efforts. We also thank the contact persons at the participating schools for their effort in preparation of the data collection. The authors gratefully acknowledge the lectorial assistance of Andrew Rausch in the preparation of this manuscript.

\section{References}

1. Zwart JA, Dyb G, Holmen TL, Stovner LJ and Sand T. The prevalence of migraine and tension-type headaches among adolescents in Norway. The Nord-Trøndelag Health Study (Head-HUNT-Youth), a large population-based epidemiological study. Cephalalgia 2004; 24 : 373-379.

2. Laurell K, Larsson B and Eeg-Olofsson O. Prevalence of headache in Swedish schoolchildren, with a focus on tension-type headache. Cephalalgia 2004; 24: 380-388.

3. Fendrich K, Vennemann M, Pfaffenrath V, et al. Headache prevalence among adolescents-the German DMKG headache study. Cephalalgia 2007; 27: 347-354.

4. Kröner-Herwig B, Heinrich M and Morris L. Headache in German children and adolescents: a population-based epidemiological study. Cephalalgia 2007; 27: 519-527.

5. Passchier $\mathbf{J}$ and Orlebeke $\mathbf{J F}$. Headaches and stress in schoolchildren: an epidemiological study. Cephalalgia 1985; 5: 167-176.

6. Larsson B. The role of psychological, health-behaviour and medical factors in adolescent headache. Dev Med Child Neurol 1988; 30: 616-625.

7. Carlsson J, Larsson B and Mark A. Psychosocial functioning in schoolchildren with recurrent headaches. Headache 1996; 36: 77-82.

8. Carlsson J. Prevalence of headache in schoolchildren: relation to family and school factors. Acta Paediatr 1996; 85: 692-696.

9. Hjern A, Alfven G and Ostberg V. School stressors, psychological complaints and psychosomatic pain. Acta Paediatr 2008; 97: 112-117.

10. Alfven G, Ostberg V and Hjern A. Stressor, perceived stress and recurrent pain in Swedish schoolchildren. J Psychosom Res 2008; 65: 381-387.

11. Sundblad GB, Jansson A, Saartok T, Renström P and Engström LM. Self-rated pain and perceived health in relation to stress and physical activity among schoolstudents: a 3-year follow-up. Pain 2008; 136: 239-249.

12. Björling EA. The momentary relationship between stress and headaches in adolescent girls. Headache 2009; 49: 1186-1197. 
13. Karwautz A, Wöber C, Lang T, et al. Psychosocial factors in children and adolescents with migraine and tension-type headache: a controlled study and review of the literature. Cephalalgia 1999; 19: 32-43.

14. Laurell K, Larsson B and Eeg-Olofsson O. Headache in schoolchildren: association with other pain, family history and psychosocial factors. Pain 2005; 119: $150-158$.

15. Bener A, Uduman SA, Qassimi EM, et al. Genetic and environmental factors associated with migraine in schoolchildren. Headache 2000; 40: 152-157.

16. Kaynak Key FN, Donmez S and Tuzun U. Epidemiological and clinical characteristics with psychosocial aspects of tension-type headache in Turkish college students. Cephalalgia 2004; 24: 669-674.

17. Waldie KE. Childhood headache, stress in adolescence, and primary headache in young adulthood: a longitudinal cohort study. Headache 2001; 41: 1-10.

18. Schulz P, Schlotz W and Becker P. Trier inventory of chronic stress [in German], 1st edn. Goettingen: Hogrefe, 2004.

19. Headache Classification Subcommittee of the International Headache Society. The International Classification of Headache Disorders: 2nd edition. Cephalalgia 2004; 24(Suppl 1): 9-160.

20. Kurth BM, Kamtsiuris P, Hölling H, et al. The challenge of comprehensively mapping children's health in a nation-wide health survey: design of the German KiGGS-Study. BMC Public Health 2008; 8: 196.

21. Headache Classification Committee. Olesen J, Bousser $\mathrm{MG}$, Diener HC, et al. New appendix criteria open for a broader concept of chronic migraine. Cephalalgia 2006; 26: $742-746$.

22. Waldie KE and Poulton R. Physical and psychological correlates of primary headache in young adulthood: a 26 year longitudinal study. J Neurol Neurosurg Psychiatry 2002; 72: 86-92.

23. Brighina $F$ and Fierro B. Cortical hypoactivity or reduced efficiency of cortical inhibition in migraine? Cephalalgia 2007; 27: 187-188.

24. Sauro KM and Becker WJ. The stress and migraine interaction. Headache 2009; 49: 1378-1386.

25. Siniatchkin M, Averkina N, Andrasik F, Stephani U and Gerber WD. Neurophysiological reactivity before a migraine attack. Neurosci Lett 2006; 400: 121-124.

26. Siniatchkin M, Andrasik F, Kropp P, et al. Central mechanisms of controlled-release metoprolol in migraine: a double-blind, placebo-controlled study. Cephalalgia 2007; 27: 1024-1032.

27. Jensen R. Pathophysiological mechanisms of tension-type headache: a review of epidemiological and experimental studies. Cephalalgia 1999; 19: 602-621.

28. Anttila P, Sourander A, Metsähonkala L, Aromaa M, Helenius H and Sillanpää M. Psychiatric symptoms in children with primary headache. $J$ Am Acad Child Adolesc Psychiatry 2004; 43: 412-419.

29. Mazzone L, Vitiello B, Incorpora G and Mazzone D. Behavioural and temperamental characteristics of children and adolescents suffering from primary headache. Cephalalgia 2006; 26: 194-201.
30. Milde-Busch A, Boneberger A, Heinrich S, et al. Higher prevalence of psychopathological symptoms in adolescents with headache. A population-based cross-sectional study. Headache 2010; 50: 738-748.

31. Bandell-Hoekstra I, Abu-Saad HH, Passchier J and Knipschild P. Recurrent headache, coping, and quality of life in children: a review. Headache 2000; 40: 357-370.

32. Houle T and Nash JM. Stress and headache chronification. Headache 2008; 48: 40-44.

33. Nash JM and Thebarge RW. Understanding psychological stress, its biological processes, and impact on primary headache. Headache 2006; 46: 1377-1386.

34. Breslau N, Chilcoat HD and Andreski P. Further evidence on the link between migraine and neuroticism. Neurology 1996; 47: 663-677.

35. Köhler $\mathrm{T}$ and Haimerl C. Daily stress as a trigger of migraine attacks: results of thirteen single-subject studies. J Consult Clin Psychol 1990; 58: 870-872.

36. Levor RM, Cohen MJ, Naliboff BD, McArthur D and Heuser G. Psychosocial precursors and correlates of migraine headache. J Consult Clin Psychol 1986; 54: 347-353.

37. Marlowe N. Stressful events, appraisal, coping and recurrent headache. J Clin Psychol 1998; 54: 247-256.

38. Sorbi MJ, Maassen GH and Spierings EL. A time series analysis of daily hassles and mood changes in the 3 days before the migraine attack. Behav Med 1996; 22: 103-113.

39. Spierings EL, Sorbi M, Haimowitz BR and Tellegen B. Changes in daily hassles, mood, and sleep in the 2 days before a migraine headache. Clin J Pain 1996; 12: $38-42$.

40. Spierings EL, Sorbi M, Maassen GH and Honkoop PC. Psychophysical precedents of migraine in relation to the time of onset of the headache: the migraine time line. Headache 1997; 37: 217-220.

41. Spierings EL, Ranke AH and Honkoop PC. Precipitating and aggravating factors of migraine versus tension-type headache. Headache 2001; 41: 554-558.

42. Zivadinov R, Willheim K, Sepic-Grahovac D, et al. Migraine and tension-type headache in Croatia: a population-based survey of precipitating factors. Cephalalgia 2003; 23: 336-343.

43. Fernandez E and Sheffield J. Relative contributions of life events versus daily hassles to the frequency and intensity of headaches. Headache 1996; 36: 595-602.

44. Holm JE, Lokken C and Myers TC. Migraine and stress: a daily examination of temporal relationships in women migraineurs. Headache 1997; 37: 553-558.

45. Bigal ME and Lipton RB. Modifiable risk factors for migraine progression. Headache 2006; 46: 1334-1343.

46. Langeveld JH, Koot HM and Passchier J. Do experienced stress and trait negative affectivity moderate the relationship between headache and quality of life in adolescents? J Pediatr Psychol 1999; 24: 1-11.

47. Barton-Donovan $\mathrm{K}$ and Blanchard EB. Psychosocial aspects of chronic daily headache. $J$ Headache Pain 2005; 6: 30-39. 
48. Buddeberg-Fischer B, Stamm M, Buddeberg C and Klaghofer R. Chronic stress experience in young physicians: impact of person- and workplacerelated factors. Int Arch Occup Environ Health 2010; 83: 373-379.

49. Grulke N, Bailer $\mathrm{H}$, Blaser $\mathrm{G}$, et al. Worrying about one's job, family, financial situation and health results of a population-representative study. Psychosoc Med 2006; 3: 11.

50. Federenko IS, Schlotz W, Kirschbaum C, Bartels M, Hellhammer DH and Wüst S. The heritability of perceived stress. Psychol Med 2006; 36: 375-385.

51. Nickel C, Tanca S, Kolowos S, et al. Men with chronic occupational stress benefit from behavioural/ psycho-educational group training: a randomized, prospective, controlled trial. Psychol Med 2007; 37: 1141-1149.
52. Zarifoğlu M, Karli N and Takapilioğlu O. Can ID Migraine be used as a screening test for adolescent migraine? Cephalalgia 2008; 28: 65-71.

53. Valentinis L, Valent F, Mucchiut $\mathrm{M}$, Barbone $\mathrm{F}$, Bergonzi $P$ and Zanchin G. Migraine in adolescents: validation of a screening questionnaire. Headache 2009; 49: 202-211.

54. Hershey AD, Winner P, Kabbouche MA, et al. Use of the ICHD-II criteria in the diagnosis of pediatric migraine. Headache 2005; 45: 1288-1297.

55. Milde-Busch A, Heinrich S, Thomas S, et al. Quality of life in adolescents with headache: results from a population-based survey. Cephalalgia 2010; 30: 713.

56. Bohn V, Rathmann $\mathrm{K}$ and Richter M. Psychosocial health among children and adolescents in North Rhine Westphalia: the role of age, gender and type of school. Gesundheitswesen 2010; 72: 293-300. 